\title{
DELAYED FEEDBACK CONTROL OF NONLINEAR PHENOMENA IN INDIRECT FIELD ORIENTED CONTROL OF INDUCTION MOTOR
}

\author{
Subhankar Dam¹, Abhrajit Saha', Goutam Kumar Panda ${ }^{3}$ \\ ${ }^{1,2}$ Assistant Professor, Dept. of Electrical Engg, Birbhum Inst. of Engg.\&Tech, West Bengal, India, \\ ${ }^{3}$ Professor, Dept. of Electrical Engg, Jalpaiguri Govt. Engg. College, West Bengal, India \\ subhankardam@gmail.com, ${ }^{2}$ saha.abhrajit@gmail.com,g_panda@rediffmail.com
}

\begin{abstract}
The Indirect Field Oriented Controlled (IFOC) Induction Motor often shows the nonlinearity in time domain response of its speed and current due to the instability of the periodic orbits. The system undergoes Hopf bifurcation which is essentially caused by the unstable equilibrium points. In this work our aim is directed towards the stabilization of the unstable periodic orbits (UPOs) by continuously perturbing the system by a time delayed version of any state variable in a feedback form. The clarification of controlling the system from any periodic even chaotic mode to any stable periodic mode is presented by both numerical analysis and software simulation.
\end{abstract}

Index Terms: IFOC-IM, Hopf Bifurcation, Time Delayed Feedback Control, Control of Nonlinear Dynamics.

*****

\section{INTRODUCTION}

Judged in terms of fitness for purpose couples with simplicity, the induction motor must rank alongside the screw thread as one of mankind's best inventions. Among its various control and estimation strategies the Indirect Field Oriented Control (IFOC) is perhaps the most reliable for high dynamic performance. But the motor often possesses self-sustained oscillation due to its' nonlinear differential dynamic equations. For a particular setting of rotor time constant and constants of outer proportional-integral loop the rotor goes through Hopf Bifurcation and if the parameters are changed further and further the chaotic mode is obtained [1-4].

In this work we have proposed a time dependent feedback controller [7] to control the nonlinear phenomena and chaos in the IFOC-IM. The method is based on the stabilization of unstable periodic orbits (UPOs) embedded within a strange attractor. This is achieved by making a small time dependent perturbation in the form of feedback to an accessible system parameter. The method turned the presence of chaos into an advantage. Due to an infinite number of different UPOs embedded in a strange attractor, a chaotic system can be tuned to a large nos. of distinct periodic regimes by switching the temporal programming of small parameter perturbation to stabilize different periodic orbits. This method has been successfully applied to some practical experiments.

The rest of the paper is arranged as follows: Section-II describes the nonlinear dynamical model and control equations of the IFOC-IM. Section-III presents the system with proposed controller for controlling the nonlinearity of the motor. Both the numerical and computer simulation are researched in this section for understanding the accomplishing process of the Time Delayed Feedback Controller (TDFC) with the tested IFOC-IM model. Finally we conclude with some concluding remarks in Section-IV. For simulation purpose we have used MATLAB-SIMULINK 2009a.

\section{DYNAMICAL MODEL AND CONTROL EQUATIONS OF IFOC-IM}

We consider the indirect field oriented control with speed regulation in it's standard formulation, based on the current feed induction motor model expressed in the synchronously rotating reference frame.

$$
\begin{aligned}
& \dot{\varphi}_{\mathrm{qr}}=-\frac{\mathrm{R}_{\mathrm{r}}}{\mathrm{L}_{\mathrm{r}}} \varphi_{\mathrm{qr}}-\omega_{s 1} \varphi_{\mathrm{dr}}+\frac{\mathrm{L}_{\mathrm{m}}}{\mathrm{L}_{\mathrm{r}}} \mathrm{R}_{\mathrm{r}} \mathrm{i}_{\mathrm{qs}} \\
& \dot{\varphi}_{d r}=-\frac{R_{r}}{L_{r}} \varphi_{d r}+\omega_{s l} \varphi_{q r}+\frac{L_{m}}{L_{r}} R_{r} i_{d s} \\
& \tilde{\omega}_{\mathrm{r}}=-\frac{\mathrm{R}_{\mathrm{m}}}{\mathrm{I}}+\frac{1}{\mathrm{I}}\left[\frac{\mathrm{a}}{2} \frac{\mathrm{L}_{\mathrm{m}}}{\mathrm{L}_{\mathrm{r}}} \mathrm{n}_{\mathrm{p}}\left(\mathrm{i}_{\mathrm{qs}} \varphi_{\mathrm{dr}}-\mathrm{i}_{\mathrm{ds}} \varphi_{\mathrm{qr}}\right)-\mathrm{T}_{\mathrm{l}}\right] \ldots
\end{aligned}
$$

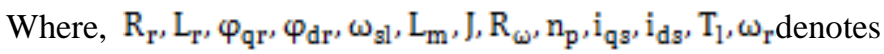
rotor resistance, rotor self inductance, quadrature axis, direct axis component of the rotor flux, slipping frequency, mutual inductance in a rotating reference frame, inertia co-efficient, rotating resistance co-efficient, no of pole pairs, quadrature axis component, direct axis component of stator current, rotor angular speed respectively. Substituting by

$$
\begin{aligned}
& a_{1}=\frac{R_{r}}{L_{r}}, a_{2}=\frac{L_{m}}{L_{r}} R_{r}, a_{a}=\frac{R_{\omega}}{I}, a_{4}=\frac{1}{I}, a_{5}=\frac{a}{2} \frac{L_{m}}{L_{r}} n_{p}, x_{1}= \\
& \varphi_{q r^{r}} x_{2}=\varphi_{d r}, u_{1}=\omega_{s I s}, u_{2}=i_{d s}, u_{d}=i_{q s}
\end{aligned}
$$


we get the dynamic model of IFOC as follows,

$\mathrm{x}_{1}=-\mathrm{a}_{1} \mathrm{x}_{1}-\mathrm{u}_{1} \mathrm{x}_{2}+\mathrm{a}_{2} \mathrm{u}_{\mathrm{a}}$

$\dot{\mathrm{x}}_{2}=-\mathrm{a}_{1} \mathrm{x}_{2}+\mathrm{u}_{1} \mathrm{x}_{1}+\mathrm{a}_{2} \mathrm{u}_{2}$

$\dot{\omega}=\mathrm{a}_{\mathrm{g}} \omega+\mathrm{a}_{4}\left[\mathrm{a}_{5}\left(\mathrm{x}_{2} \mathrm{u}_{\mathrm{a}}-\mathrm{x}_{1} \mathrm{u}_{2}\right)-\mathrm{T}_{1}\right]$

In speed regulation applications the IFOC is usually applied along with a PI speed loop. The control strategy is described by the following equations,

$\mathrm{u}_{1}=\widehat{\mathrm{a}_{1}} \frac{\mathrm{u}_{3}}{\mathrm{u}_{2}}$

$\mathrm{u}_{2}=\mathrm{u}_{2}^{0}$

$\mathrm{u}_{\mathrm{a}}=\mathrm{K}_{\mathrm{p}}\left(\omega_{\mathrm{ref}}-\omega_{\mathrm{r}}\right)+\mathrm{K}_{\mathrm{i}} \int_{0}^{\tau}\left(\omega_{\mathrm{ref}}(\tau)-\omega_{\mathrm{r}}(\tau)\right) \mathrm{d} \tau$

Where $\widehat{\mathrm{a}_{1}}, \omega_{\mathrm{ref}}, \mathrm{u}_{2}^{0}, \mathrm{~K}_{\mathrm{p}}, \mathrm{K}_{\mathrm{i}}$ denotes the estimate of inverse of rotor time constant, the constant reference velocity, constant reference for the rotor flux magnitude, the proportional and integral gains of the PI speed regulator respectively. In practical cases rotor time constant varies widely in IFOC-IM system. Assuming we have a perfect estimate of rotor time constant i.e. $\widehat{a_{1}}=a_{1}$, then we can say the control is tuned otherwise it is detuned. Therefore we define

$$
\kappa=\widehat{a_{1}} / a_{1}
$$

as the degree of tuning. It is clear that $\kappa>0$ and the control is tuned if and only if $\kappa=1$.

Defining state variables $x_{a}=\omega_{\text {ref }}-\omega_{\mathrm{r}}$ and $x_{4}=u_{a}$ then the model of whole closed loop system (1.4)-(1.6) with the control strategy (1.7)-(1.9) is a fourth order system and is written as

$\dot{\mathrm{x}}_{1}=-\mathrm{a}_{1} \mathrm{x}_{1}+\mathrm{a}_{2} \mathrm{x}_{4}-\frac{\mathrm{Ka}_{1}}{\mathrm{u}_{2}^{0}} \mathrm{x}_{2} \mathrm{x}_{4}$

$\dot{\mathrm{x}}_{2}=-\mathrm{a}_{1} \mathrm{x}_{1}+\mathrm{a}_{2} \mathrm{x}_{4}-\frac{\mathrm{Ka}_{1}}{\mathrm{u}_{2}^{0}} \mathrm{x}_{2} \mathrm{x}_{4}$

$\dot{\mathrm{x}}_{\mathrm{a}}=-\mathrm{a}_{\mathrm{a}} \mathrm{x}_{\mathrm{a}}-\mathrm{a}_{4}\left[\mathrm{a}_{5}\left(\mathrm{x}_{2} \mathrm{x}_{4}-\mathrm{u}_{2}^{0} \mathrm{x}_{1}\right)-\mathrm{T}_{1}-\frac{\mathrm{a}_{3}}{\mathrm{a}_{4}} \omega_{\mathrm{ref}}\right]$.

$\dot{\mathrm{x}}_{4}=-\mathrm{K}_{\mathrm{c}} \mathrm{x}_{\mathrm{a}}-\mathrm{K}_{\mathrm{p}} \mathrm{a}_{4}\left[\mathrm{a}_{5}\left(\mathrm{x}_{2} \mathrm{x}_{4}-\mathrm{u}_{2}^{0} \mathrm{x}_{1}\right)-\mathrm{T}_{\mathrm{l}}-\frac{\mathrm{a}_{\mathrm{a}}}{\mathrm{a}_{4}} \omega_{\mathrm{ref}}\right]$

Where,

$\mathrm{K}_{\mathrm{c}} \triangleq \mathrm{K}_{\mathrm{i}}-\mathrm{K}_{\mathrm{p}} \mathrm{a}_{\mathrm{a}}$

and we shall define the new state variables as $x_{a} \triangleq \omega_{\text {ref }}-\omega$, $\mathrm{x}_{4} \stackrel{\triangleq}{=} \mathrm{u}_{\mathrm{a}}, \mathrm{T}_{\mathrm{I}}$ is the load torque, $\mathrm{u}_{2}^{0}=$ direct axis component of the stator current, $\mathrm{a}_{1}$ to $\mathrm{a}_{5}$ are machine parameters, $\mathrm{K}_{\mathrm{p}}$ and $\mathrm{K}_{\tilde{\mathrm{I}}}$ are the proportional and integral gains of the PI speed regulator respectively. We assume that both $\omega_{r e f x}$ the speed reference and $\mathrm{T}_{\mathrm{I}}$, the load torque are constants.

The differential equations of the system are nonlinear as they contain four nonlinear terms on the right side.

Table-1: Parameters of the motor used for the simulation

\begin{tabular}{|l|l|}
\hline Parameters & Value \\
\hline$a_{1}$ & $13.67 \mathrm{~s}^{-1}$ \\
\hline$a_{2}$ & $1.56 \mathrm{Hs}^{-1}$ \\
\hline$a_{3}$ & $0.59 \mathrm{~s}^{-1}$ \\
\hline$a_{4}$ & $1176 \mathrm{~kg}^{-1} \mathrm{~m}^{-2}$ \\
\hline$a_{5}$ & 2.86 \\
\hline$w_{r e f}$ & $181.1 \mathrm{rad} / \mathrm{seC}$ \\
\hline$T_{l}$ & $2.3 \mathrm{~N} . \mathrm{M}$ \\
\hline$u_{2}^{0}$ & $4 A$ \\
\hline
\end{tabular}

Simulating equations (1.11-1.14) with the above mentioned machine parameters we get the following time responses of speed error $(\mathrm{x} 3)$ and quadrature component of stator current (x4) by successively changing $\kappa$. From the simulation results it is clear thatif $\kappa$ (bifurcation parameter)is changed continuously the system undergoes successive bifurcations and finally goes into chaos. The phase portraits between $\mathrm{x} 3$ and $\mathrm{x} 4$ also proves the change in periodicity with the change in bifurcation parameter.
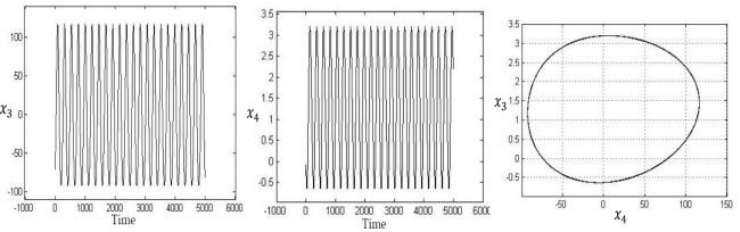

Fig-1a: for $\kappa=2.8$ the system is of period 1
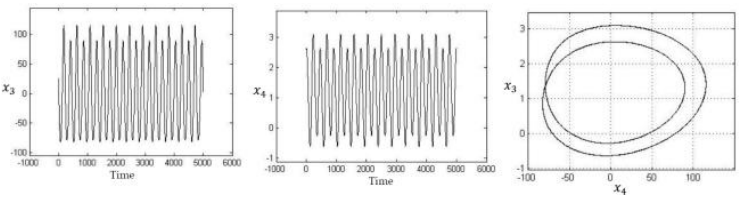

Fig-1b: for $\kappa=3.1$ the system is of period 2
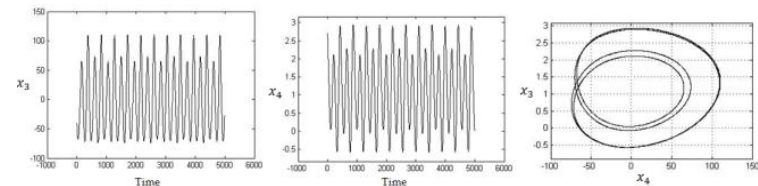

Fig-1c: for $\kappa=3.39$ the system is of period 4 

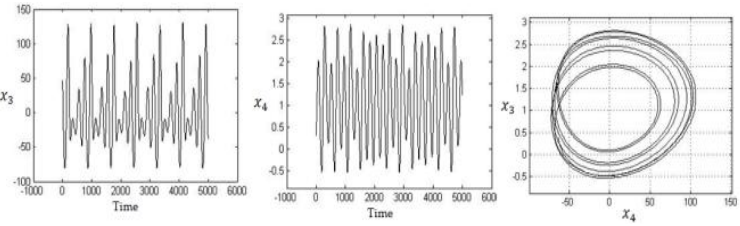

Fig-1d: for $\kappa=3.449$ the system is of period 8
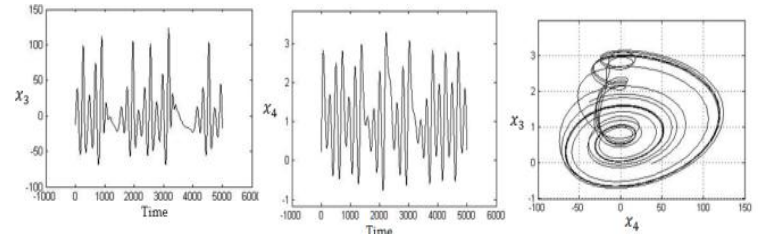

Fig-1e: for $\kappa=3.5499$ the system is chaotic

\section{CONTROL OF NONLINEAR PHENOMENON BY TDFC}

Recently, there has been a significant interest in controlling chaotic systems. Among the control strategies used to suppress chaos, perhaps the most well-known is the Ott-GrebogiYorke method (Ott et al. 1990). A special feature of a chaotic system is that it possesses a dense set of bounded but typically unstable periodic orbits (UPO), which a non-chaotic nonlinear system generally does not have. Thus, to take advantage of chaos, controlling a chaotic orbit to stabilize a particular UPO is beneficial to generate the oscillation with desired periods. Pyragas et al. presented a very simple but quite novel approach to stabilize any UPO by feedback method. The feedback used in this control strategy is based on the difference between the current state of the system and a time delayed one. The delay constant is chosen to be equal to the period of target UPO, which is assumed to be known in priori. In this section we have presented a time dependent selfcontrolling feedback controller which feeds back the delayed version of any state variable of the dynamical system of IFOC-IM itself. For the feedback purpose we choose the quadrature component of stator current (x4) among the state variables. The state equations of the system so become,

$\tilde{x}_{1}=-a_{1} x_{1}+a_{2} x_{4}-\frac{\mathrm{Ka}_{1}}{u_{2}^{0}} x_{2} x_{4}$

$\dot{x}_{2}=-a_{1} x_{1}+a_{2} x_{4}-\frac{K_{1}}{u_{2}^{0}} x_{2} x_{4}$

$\dot{x}_{a}=-a_{a} x_{a}-a_{4}\left[a_{5}\left(x_{2} x_{4}-u_{2}^{0} x_{1}\right)-T_{1}-\frac{a_{3}}{a_{4}} \omega_{r e f}\right] \ldots$

$\dot{\mathrm{x}}_{4}=-\mathrm{K}_{\mathrm{c}} \mathrm{x}_{\mathrm{a}}-\mathrm{K}_{\mathrm{p}} \mathrm{a}_{4}\left[\mathrm{a}_{5}\left(\mathrm{x}_{2} \mathrm{x}_{4}-\mathrm{u}_{2}^{0} \mathrm{x}_{1}\right)-\mathrm{T}_{\mathrm{I}}-\right.$ $\left.\frac{a_{3}}{a_{4}} \omega_{\text {ref }}\right]$

$+\mathrm{kf}(\mathrm{x} 4(\mathrm{t}-\tau)-\mathrm{x} 4) \ldots \ldots(1.14)$

We define $\mathrm{kf}$ and $\tau$ as feedback gain and time delay of the time delayed feedback controller.
Putting $\dot{x}_{1}, \dot{x}_{2}, \dot{x}_{3}, \dot{x}_{4}=0$ we get the following equilibrium points,

$$
\begin{aligned}
& x_{1}^{*}=-1.825896123 x_{4}^{*}(x-1) /\left(16+x^{2}\left(x_{4}^{*}\right)^{2}\right) \\
& x_{2}^{*}=-0.4564740307\left(16+x\left(x_{4}^{*}\right)^{2}\right) /\left(16+x^{2}\left(x_{4}^{*}\right)^{2}\right) \\
& x_{a}^{*}=0
\end{aligned}
$$

Putting these in the following equation $x_{4}^{*}$ is obtained,

$\left(k_{i}-k_{p} a_{a}\right) x_{a}^{*}-k_{p} c_{4}\left(c_{5}\left(x_{2}^{*} x_{4}^{*}-u_{2}^{0} x_{1}^{*}\right)-T_{1}-c_{a} / c_{4} \omega_{\text {ref }}\right)=0$

Setting different values for delayed time and feedback gain different UPOs are stabilized and that periodic orbit is obtained for any value of bifurcation parameter such that,for any arbitrary value of feedback gain $(\mathrm{Kf}=20)$,

\begin{tabular}{|c|c|}
\hline $\begin{array}{c}\text { Value of } \\
\text { delayed time } \\
(\tau)\end{array}$ & Period of the system with TDFC \\
\hline 0.1 & Stable at equilibrium point \\
\hline 0.03 & 1 \\
\hline 0.015 & 2 \\
\hline 0.01 & 4 \\
\hline
\end{tabular}

Choosing $\kappa=3.6$ for which the system becomes chaotic without the TDFC controller, we apply the feedback of any state variable in the delayed form at a particular instant of time. By simulation we get the following results of state variables $\mathrm{x} 3 \& \mathrm{x} 4$,

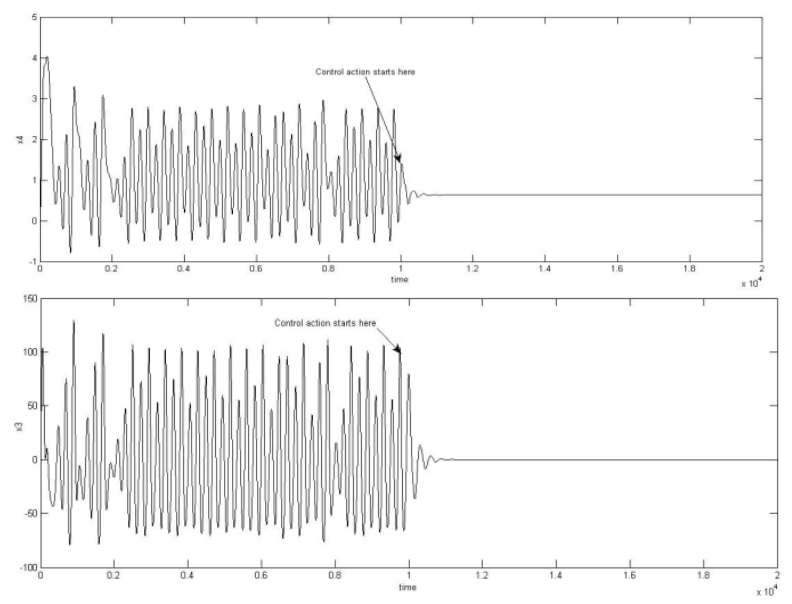

Fig.2a: for a delay time of $0.1 \mathrm{sec}$ the chaotic system stabilizes at the equilibrium points $\left(\tilde{\mathbf{x}}_{3} \& \dot{\mathbf{x}}_{4}\right)$ 


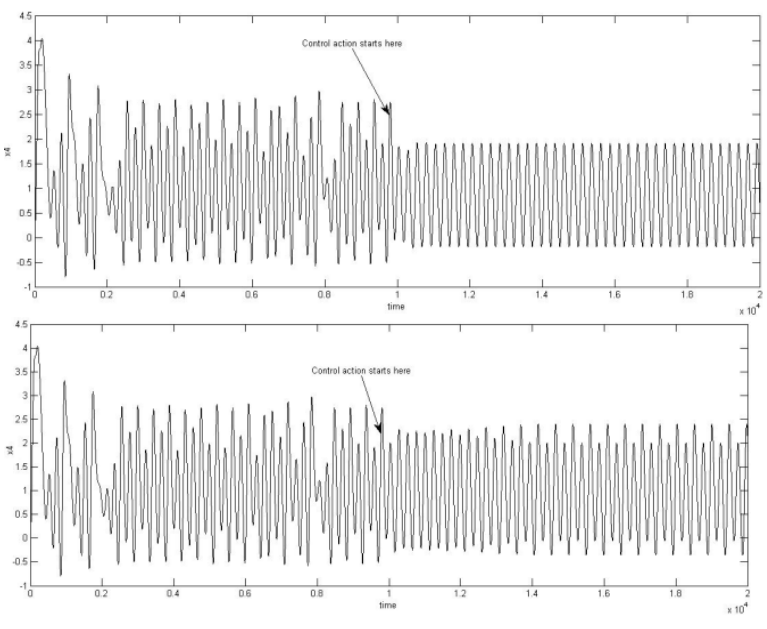

Fig.2b: for a delay time of $0.03 \mathrm{sec}$ the chaotic system becomes period- 1 system
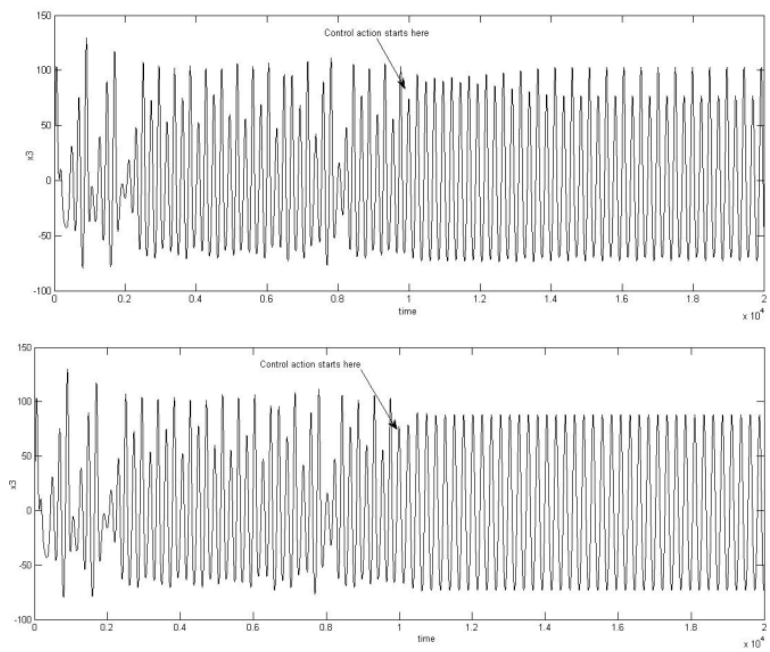

Fig.2c: for a delay time of $0.015 \mathrm{sec}$ the chaotic system becomes period-2 system

\section{CONCLUSIONS}

The main goal of this work was to study the dynamical behavior of IFOC-IM drive when a feedback controller feds a delayed version of any of the state variables into the system. The controller quenches the nonlinear phenomena which the system inherently exhibits of. To meet this we first simulate the system both mathematically and computer stimulatory. We have presented the MATLAB-SIMULINK results. Then to control the nonlinearity of the system we have applied the time delayed feedback controller and experimental results shows the successful implementation of the control scheme.

\section{REFERENCES}

[1] A.S. Bazanella and R. Reginatto, "Robustness margins for indirect field-oriented control of induction motors," IEEE transactions on automatic control, vol. 45, No.6,June. 2000.

[2] A.S. Bazanella, R. Reginatto, and R.Valiati, "On Hopf bifurcations in indirect field oriented control of induction motors:Designing a robust PI controller," Conference on Decision \& Control, Phoneix, Arizona USA,Dec.1999.

[3]Yongyao Lu, Wensheng Li, Hongmei Li, "Hopf Bifurcation and it's Control in an Induction Motor System with Indirect Field Oriented Control" IEEE transactions 2009.

[4] Francisco Gordillo, Francisco Salas, Romeu Reginatto, and Javier Aracil, "Hopf bifurcation in indirect field-oriented control of inductionmotors," Automatica, vol.38, pp. 829-835, 2002.

[5] P.A.S. De Wit, R.Ortega, and I.Mareels. "Indirect field oriented control of induction motors is robust globally stable". Automatica, 32(10):1393-1402,1996.

[6]A.S. Bazanella and R. Reginatto, “instability mechanisms in indirect field oriented control drives: theory and experimental results" 15th Triennial World Congress, Barcelona, Spain.

[7] K Pyragas, Phys. Lett. A170, 421 (1992)

[8] E Ott, C Grebogi and J A Yorke, Phys. Rev. Lett. 64, 1196 (1990)

\section{BIOGRAPHIES:}
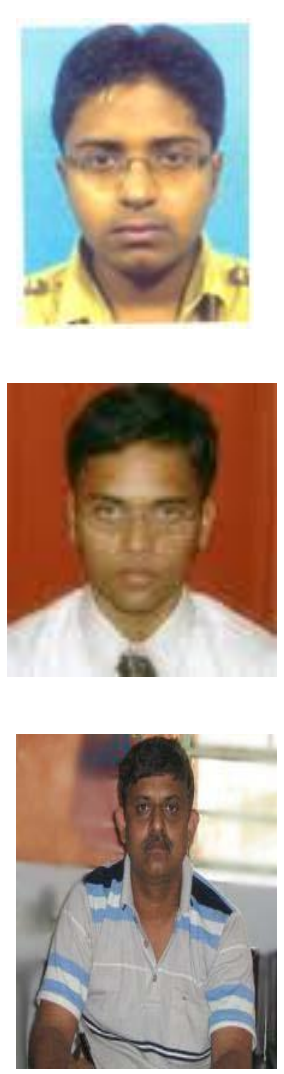

Subhankar Dam is currently an Assistant Professor of Dept. of Electrical Engineering, Birbhum Institute of Engg. \& Tech, West Bengal, India. He got his M.Tech from Jalpaiguri Govt. Engg. College. His fields of interest are Power Electronics, Electric Drives, Nonlinear Dynamics \& Chaos, Field Theory.

Abhrajit Saha is currently an Assistant Professor of Dept. of Electrical Engineering, Birbhum Institute of Engg. \& Tech, West Bengal, India. He got his M.Tech from Jalpaiguri Govt. Engg. College. His fields of interest are Power Electronics, Electric Drives, Nonlinear Dynamics \& Chaos.

Goutam kumar Panda holds $\mathrm{PhD}$ degree from University of North Bengal. $\mathrm{He}$ is presently working as Professor in Electrical Engg. Dept. of Jalpaiguri Govt. Engineering College, West Bengal, India. His main areas of Research are presently Nonlinear Dynamics in Power Electronics and Drives. Control of Bifurcation and chaos 